Surface Science Letters

\title{
A new ethylene glycol-silane monolayer for highly-specific DNA detection on Silicon Chips
}

\author{
Sandro Carrara ${ }^{\mathrm{a}, *}$, Andrea Cavallini ${ }^{\mathrm{a}}$, Yuki Maruyama ${ }^{\mathrm{b}}$, Edoardo Charbon ${ }^{\mathrm{a}, \mathrm{b}}$, Giovanni De Micheli ${ }^{\text {a }}$ \\ a EPFL, Swiss Federal Institute of Technology, Lausanne (CH), Switzerland \\ ${ }^{\mathrm{b}}$ Technical University of Delft (NL), The Netherlands
}

\section{A R T I C L E I N F O}

\section{Article history:}

Received 22 January 2010

Accepted 30 August 2010

Available online 6 September 2010

\section{Keywords:}

AFM

Ethylene-glycol materials

Silanes

Silicon chip

Fluorescence

\begin{abstract}
A B S T R A C T
Monolayer thin films with ethylene-glycol function onto gold surfaces by using thiols have been extensively investigated. They have been proposed as precursors for applications to bio-detection, where their hydrophilic character improves both specificity and sensitivity. The aim of this letter is to characterize ethylene-glycol monolayer precursors formed onto silicon chips by using silanes. The importance of the ethylene-glycol function is demonstrated by comparing with the well known 3-Aminopropyltriethoxysilane. The different nano-scale structures of the two precursor monolayers are investigated by using atomic force microscopy (AFM). Longer, wider, and deeper grooves were measured in the images acquired on 3-Aminopropyltriethoxysilane. Fluorescence investigation demonstrates that the presence of ethylene-glycol function improves target hybridization onto silicon chips, assuring highly-specific detection of DNA.
\end{abstract}

(c) 2010 Elsevier B.V. All rights reserved.

\section{Introduction}

A pH imager realized with a CMOS chip has been recently realized [1] for measuring two-dimensional distributions and for real-time dynamic imaging of various chemical reactions. This technology was very recently proposed both for enhanced glucose sensing [2] and for DNA detection [3]. However, false positive signals from mismatching DNA were also acquired (Fig. 3(d) in Ref. [3]) clearly showing that the probe surface is not specific enough. Moreover, overlapping ranges in acquired voltages were registered for match and mismatch DNA (Fig. 4(a) and (b) in [3]). This means that the acquired signals do not distinguish among specific hybridization and non-specific adsorption of DNA onto the chip surface. A similar situation has also been observed in fully-electronic capacitance detection of DNA onto gold surfaces (Fig. 12 in [4]).

In the latter case, the poor detection quality has been related to the nano-scale properties of DNA probe films [5]. In particular, AFM investigations have shown that DNA probe film presents grooves at the nano-scale. These grooves cross the entire probe film, providing conducting pathways to solution ions. These conductive pathways affect the capacitance detection and cause time instabilities and large detection errors. Capacitance DNA detection onto gold has been highly-improved by using ethylene-glycol thiol monolayers as precursors for probe anchoring [6]. These films do not show deep grooves crossing the film in the structure at the nano-scale [7]. These

\footnotetext{
* Corresponding author.

E-mail address: sandro.carrara@epfl.ch (S. Carrara).
}

special precursor monolayers present carboxyl groups for probe anchoring as well as hydroxyl groups for repelling non-specific DNA.

This letter proposes a new kind of ethylene-glycol silane monolayer with properties similar to those demonstrated by ethylene-glycol thiols onto gold and shows that this film is suitable for highly-specific DNA detection onto a silicon chip.

\section{Experimental}

\subsection{Chemicals}

Special ethylene-glycol silanes terminated with amine and methoxyl groups were designed by us and synthesized by Prochimia, Poland. Maleimide-NHS cross-linker was purchased from Prochimia. 3-Aminopropyltriethoxysilane (APTES), $\mathrm{NaCl}, \mathrm{Na}_{2} \mathrm{HPO}_{4}, \mathrm{KH}_{2} \mathrm{PO}_{4}, \mathrm{KCl}$ (used to prepare phosphate buffered saline - PBS), $\mathrm{H}_{2} \mathrm{O}_{2}$ (50\%), ethylenediaminetetraacetic acid (EDTA), and Tris(hydroxymethyl) aminomethane (TRIS) buffer were purchased by Sigma, Switzerland. Dimethyl sulfoxide (DMSO) was purchased from Apllichem, Germany. Different DNA short oligos, with different fluorescence markers, were supplied by MWG, Germany.

\subsection{Monolayer formation}

All substrates were pre-cleaned with a pirañha solution (3:1 mixture of $\mathrm{H}_{2} \mathrm{SO}_{4}$ and $\mathrm{H}_{2} \mathrm{O}_{2}$ ). Self-assembled monolayers ( $\mathrm{SAM}$ ) without ethylene-glycol function were obtained from a solution of APTES $\left(\left(\mathrm{C}_{2} \mathrm{H}_{5} \mathrm{O}\right)_{3} \mathrm{Si}\left(\mathrm{CH}_{2}\right)_{3} \mathrm{NH}_{2}-98 \%\right.$ purity). Ethylene-glycol SAM was prepared from a $2 \mathrm{mM}$ DMSO solution made by mixing $1.96 \mathrm{mM}$ of repelling silane $\left(\mathrm{CH}_{3} \mathrm{O}\right)_{3} \mathrm{Si}\left(\mathrm{CH}_{2}\right)_{11}\left(\mathrm{OCH}_{2} \mathrm{CH}_{2}\right)_{3} \mathrm{OCH}_{3}$ and $0.04 \mathrm{mM}$ of 
silane $\left(\mathrm{CH}_{3} \mathrm{O}\right)_{3} \mathrm{Si}\left(\mathrm{CH}_{2}\right)_{11}\left(\mathrm{OCH}_{2} \mathrm{CH}_{2}\right)_{3} \mathrm{NH}_{2}$. Samples of the two kinds of SAM were prepared by immersion of substrates in the solutions and incubated overnight in the dark, at $4{ }^{\circ} \mathrm{C}$ in case of APTES, and at room temperature in case of ethylene-glycol SAM. After the monolayer formation, the samples were rinsed and sonicated for 10 min, washed with Milli- $Q$ water, and dried under nitrogen flux. Sonications were performed in ethanol for the APTES and in Milli-Q water for ethylene-glycol SAM. Films were formed onto silicon nitride, oxide, and CMOS designed chip for fluorescence imaging while they were formed onto silicon nitride, oxide, and mica for AFM investigation.

\subsection{DNA probe anchoring}

After SAM formation, the surfaces were treated with a solution of Maleimide-NHS $0.4 \mathrm{mM}$, dissolved in PBS $100 \mathrm{mM}+$ EDTA $2 \mathrm{mM}$, pH 7.2, for $1 \mathrm{~h}$. The samples were then rinsed with a solution of PBS $100 \mathrm{mM}$, pH 7.2, for $5 \mathrm{~min}$ in order to remove the excess cross-linker. Once cleaned, the slides were incubated for $1 \mathrm{~h}$ at room temperature with a $3 \mathrm{mM}$ solution of probe DNA (modified at the $5^{\prime}$ with a thiol group and at the $3^{\prime}$ end with a fluoresceine molecule) in PBS $100 \mathrm{mM}$, EDTA $2 \mathrm{mM}, \mathrm{pH}$ 7.2. The samples were then rinsed with Milli-Q water for $5 \mathrm{~min}$ to remove non-specific binding and dried under nitrogen flux.

\subsection{DNA target hybridization}

Solutions $1 \mathrm{mM}$ of target and non-specific DNA in TRIS $10 \mathrm{mM}$, EDTA $1 \mathrm{mM}$, and $\mathrm{NaCl} 1 \mathrm{M}, \mathrm{pH} 8$, were first pre-heated at $70{ }^{\circ} \mathrm{C}$. The solution was then spotted onto the probe-functionalized surfaces in aliquots of $1 \mu \mathrm{l}$ and incubated at room temperature in controlled humidity conditions for $1 \mathrm{~h}$. The samples were then rinsed for $3 \mathrm{~min}$ with a solution of TRIS $10 \mathrm{mM}$, EDTA $1 \mathrm{mM}$, for $3 \mathrm{~min}$, to remove the non-specific binding, rinsed for a few seconds with Milli-Q water in order to remove salts, and then dried under nitrogen flux.

\subsection{Fluorescent imaging}

The dry samples were analyzed with a Typhoon Trio scanner equipped with a variable mode imager - Amersham Biosciences. Fluoresceine signal (probe DNA) was acquired using a blue excitation laser $(\lambda=488 \mathrm{~nm})$ and a low-pass filter $(\lambda=526 \mathrm{~nm})$. Cy5 signal (target and non-target DNA) was acquired using a red excitation laser $(\lambda=633 \mathrm{~nm})$ and a band pass filter $(\lambda=670 / 30 \mathrm{~nm})$. For some experiments, TAMRA was also used as chromophore of non-target DNA, using a green excitation laser $(\lambda=532 \mathrm{~nm})$ and a band pass filter $(\lambda=580 / 30 \mathrm{~nm})$.

\subsection{AFM measurements}

Atomic force microscopy (AFM) images were acquired in tapping mode by using PointProbe nanocontact silicon probes on a Nanoscope IIIa SFM system equipped with a multimode head and a type-A piezoelectric scanner - Veeco, Santa Barbara, CA, USA. The images were acquired in Milli-Q water and in PBS buffer by using a 'liquid cell'. Raw images were only processed for background removal (flattening).

\section{Results and discussion}

Fig. 1 shows AFM investigation of APTES monolayer. Fig. 1(A) shows imaging on a $300 \mathrm{~nm} \times 300 \mathrm{~nm}$ region and highlights the area used for line analysis. The image has a root means square (RMS) roughness equal to $0.45 \pm 0.06 \mathrm{~nm}$. The figure clearly shows large and long grooves. Fig. 1(B) shows the average profile calculated on the area highlighted in Fig. 1(A). The profile demonstrates that the shown
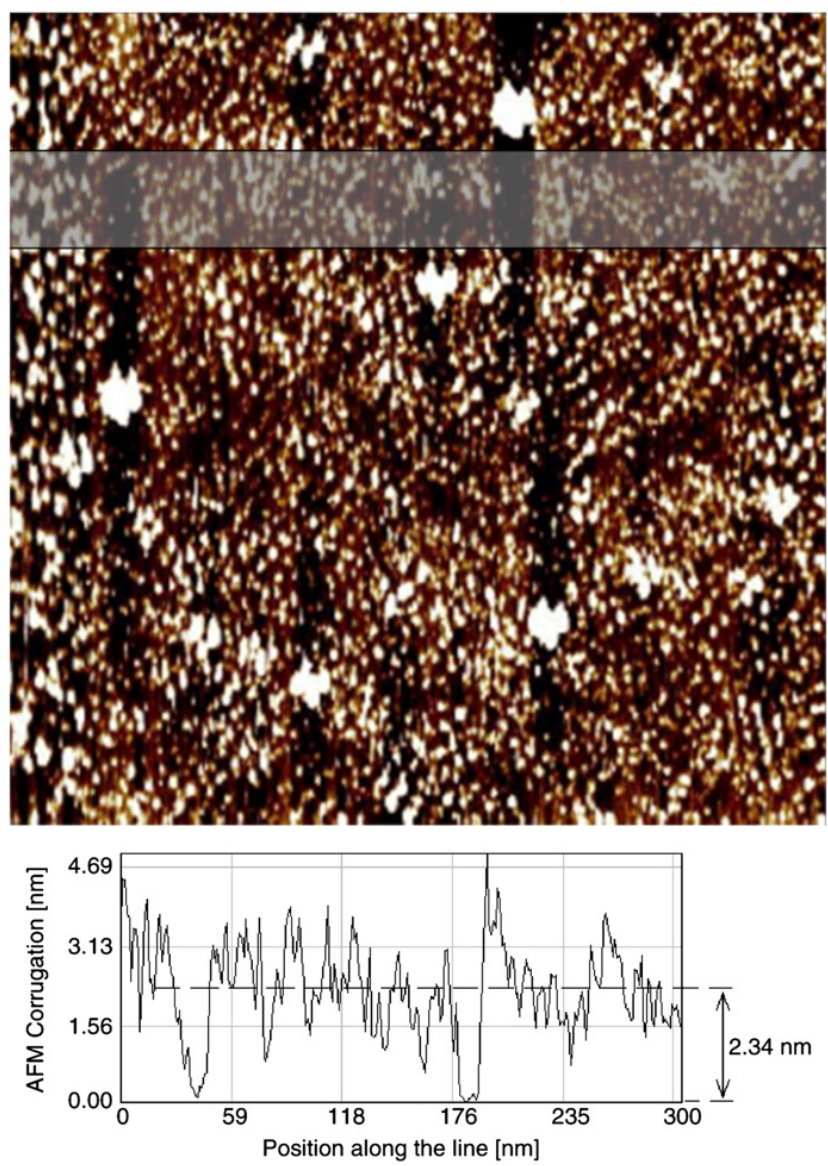

Fig. 1. AFM image (A) and profile (B) of an APTES monolayer onto mica presenting large and wide grooves. The image size is $300 \mathrm{~nm} \times 300 \mathrm{~nm}$, while the grey-level scale corresponds to $5 \mathrm{~nm}$ in surface corrugation. The image was acquired in PBS. The profile is the average of different profiles acquired on a $0.6 \mathrm{~nm}$ large region (this region is shown in A).

grooves are as deep as the whole films. This is because the shown holes are more than $2 \mathrm{~nm}$ deep, a value that is even larger than the expected height of APTES molecules that is equal to $0.8 \pm 0.1 \mathrm{~nm}$ [10]. The presence of hydrogenated alkane molecules affects the apparent AFM thickness for the APTES films, and this is the reason because it is not possible to have quantitative estimations by comparing profiles in AFM images [11,12]. Nevertheless, grooves crossing the entire layer are usually evaluated in AFM images of thin films [7,13]. Therefore, we may conclude that the grooves shown in Fig. 1(A) are crossing the entire APTES monolayer. The average depth of these grooves was estimated equal to $1.31 \pm 0.14 \mathrm{~nm}$. Images acquired on APTES also show grooves with an average length of $52 \pm 20 \mathrm{~nm}$, and an average width of $16.8 \pm 5.2 \mathrm{~nm}$

Fig. 2(A) shows a similar AFM image acquired on a $300 \mathrm{~nm} \times 300 \mathrm{~nm}$ region of an ethylene-glycol silane monolayer and the area for the line analysis. This second image clearly shows a much more densely packed film, where large and long grooves are not present. Surprisingly, the film RMS roughness was estimated almost equal to that of APTES. In fact, a value of $0.60 \pm 0.07$ was registered on ethylene-glycol, which is even larger than that of $0.45 \pm 0.06 \mathrm{~nm}$ registered on APTES. The two values are not statistically different from each other at 99\% (3 times the standard deviations) and they are higher than the range $0.28-0.39 \mathrm{~nm}$ registered on silicon wafers [9]. Thus, both the films present a high corrugation due to the nature of silanes. However, the average depth of grooves on ethylene-glycol films is only $1.06 \pm 0.17 \mathrm{~nm}$, a value smaller than that found on APTES, which is a shorter molecule. Therefore, we 

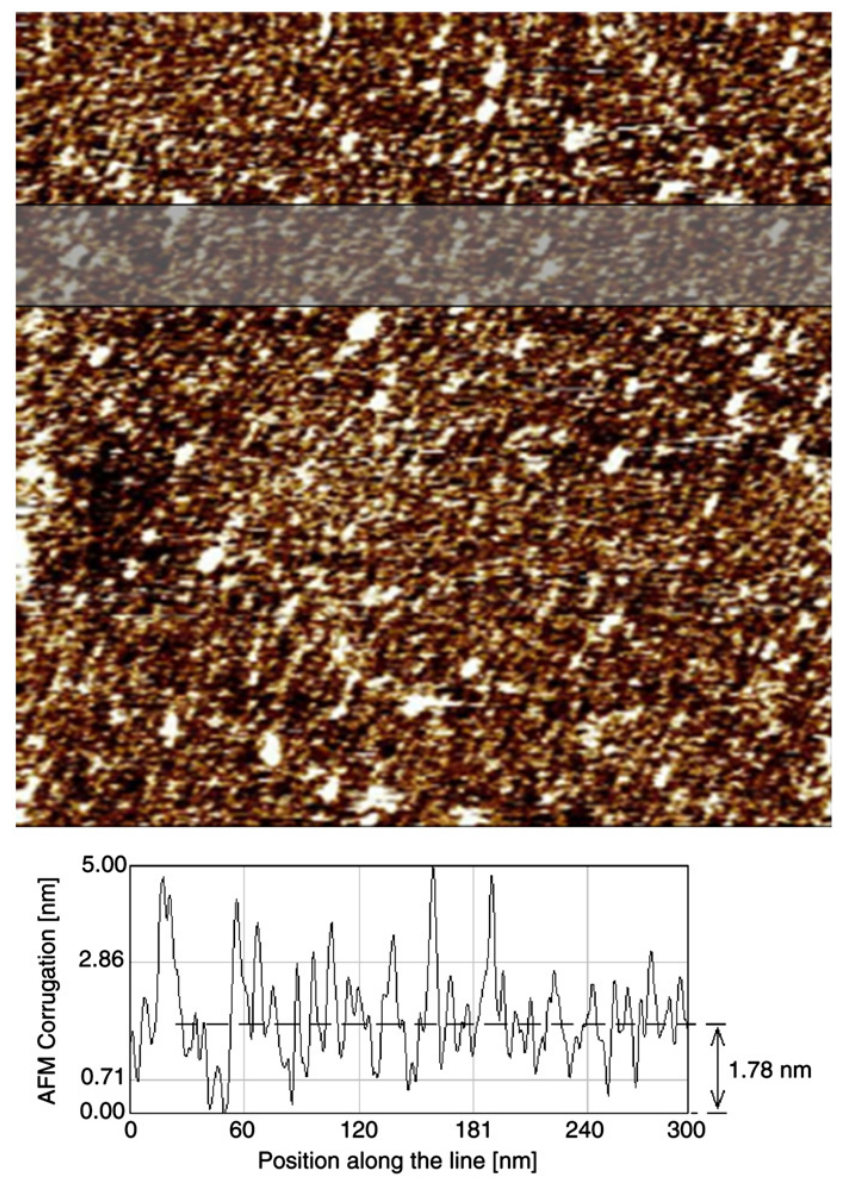

Fig. 2. AFM image (A) and profile (B) of an EG-silane monolayer onto mica, which does not present deep grooves. The image size is $300 \mathrm{~nm} \times 300 \mathrm{~nm}$, while the grey-level scale corresponds to $5 \mathrm{~nm}$ in surface corrugation. The image was acquired in PBS. The profile is the average of different profiles acquired on a $0.6 \mathrm{~nm}$ large region (this region is shown in A).

may conclude that the grooves of Fig. 1(A) are crossing the whole APTES film while those in Fig. 2(A) are not crossing the film. The average length of the grooves in ethylene-glycol monolayer is only $19 \pm 14 \mathrm{~nm}$, and the average width is $5.1 \pm 1.8 \mathrm{~nm}$. So, the average length and width are also smaller for ethylene-glycol than for APTES. Similar results by comparison were observed with ethylene-glycol thiols onto gold [7].

These nano-scale features of precursor films are reflected in the behavior of probes surfaces during DNA detection. Indeed, Fig. 3 presents the different results that we registered with these precursor films when we immobilized DNA probes onto the CMOS biochips. Fig. 3(A) presents the chip used for this test. It is exactly the same chip previously used for DNA detection with the charge transfer technique [3]. The two different SAM precursors were formed onto the CMOS chips. Then, the DNA probes, target, and non-target were deposited in smaller drops, which cover only a small surface portion. Fig. 3(B) and (C) clearly show spots in the right chip area that corresponds to target DNA hybridized to probes. However, Fig. 3(B) shows also a large fluorescent signal in the area just close to the spot where the DNA probes were immobilized and the non-specific DNA was dispersed. The signal is not exactly from the region of DNA probes but nearby. This is due to an adsorption of the DNA target directly onto APTES silanes and not to hybridization on the probes. Therefore, the nonspecific DNA surface is provided by the APTES. On the other hand, the perfectly white and clean area - surrounding the equivalent spot in Fig. 3(C) - demonstrates that ethylene-glycol assures a highly-specific DNA target recognition.

Repeated experiments on silicon slides both with silicon oxide and with silicon nitride returned the same results (data not shown). The strong role played by the new proposed precursor films in highlyspecific DNA detection relies in two molecular features: the methoxyl groups and the ethylene-glycol chains. The ethylene-glycol chains coordinate water molecules, as envisaged by ab initio calculations [14] and confirmed by both infrared spectroscopy [15] and QCM [6]. Furthermore, non-specific adsorption of DNA onto the ethylene-glycol was only obtained when the SAM was formed using only the anchoring silanes, without mixing with the repelling ones. In this case, non-specific signal was also recorded from the sample regions surrounding the probe spots. This demonstrates the key importance of mixed SAM, where the methoxyl groups $\left(\mathrm{CH}_{3}\right)$ are highly relevant to repel non-specific molecules.

When these two key features are not present into the probe layer, strong non-specific adsorption onto the silicon surface is the reason of non-specific detection of DNA by a charge transfer technique [3] and it raises doubts about the reproducibility of microarray technology [8]. This shows the key importance of both methoxyl groups and ethylene-glycol chains for a reliable DNA detection onto silicon.

\section{Conclusions}

Two different kinds of silane monolayers used as film precursors for DNA detection were investigated and presented in this letter. Monolayers with ethylene-glycol function have shown highly-specific DNA hybridization onto silicon CMOS chip. AFM imaging revealed highly-packed film structures at the nano-scale, with small grooves, which do not cross the whole film thickness. Similar AFM imaging onto shorter silane monolayer without ethylene-glycol function has

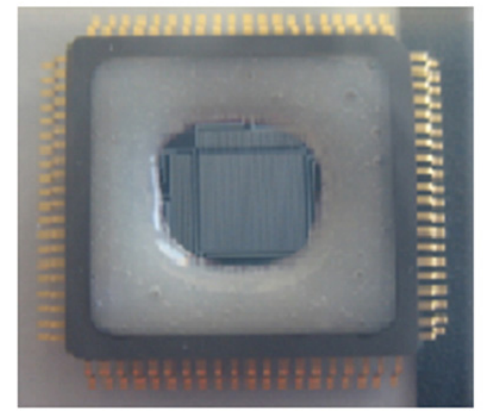

A

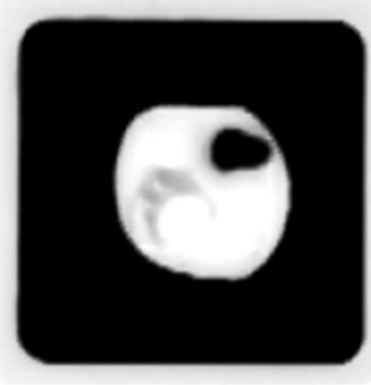

B

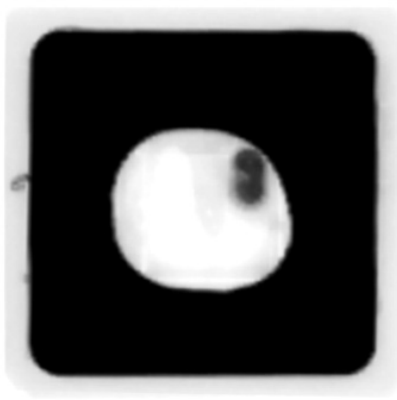

C

Fig. 3. (A) A photograph of the DNA-chip used in this investigation and functionalized with the two considered precursor monolayers. (B) Fluorescent image acquired on a chip with APTES that also present an evident signal from the region of the non-coding DNA. (C) Fluorescent image acquired on a chip with ethylene-glycol silanes that assure highly-specific DNA hybridization only from coding DNA target. 
shown larger, longer, and deeper grooves. In these films, deep grooves are widely distributed on the film surface, and they provide regions for non-specific adsorption of DNA sequences that remain trapped into the precursor film. Thus, the superior performance of ethyleneglycol silane monolayers in providing highly-specific sensors is demonstrated in CMOS chips for DNA detection.

\section{Acknowledgements}

Piotr Barski is acknowledged for the ethylene-glycol silanes. Fabrizio Benedetti, Alonso Livan and Manas Jain for AFM image acquisition. Marie Agnes Doucey for her help in fluorescent acquisitions. Kazuaki Sawada for the CMOS chip availability. The research has been supported by the EPFL - Center SI project entitled "Enabling Nano-Bio-Chip Technologies for Sensing Applications".

\section{References}

[1] T. Hizawa, K. Sawadaq, H. Takao, M. Ishida, Sensors and Actuators B 117 (2006) 509-515.
[2] S.-R. Lee, K. Sawada, Biosensors and Bioelectronics 24 (2008) 650-656.

[3] Y. Maruyama, S. Terao, K. Sawada, Biosensors and Bioelectronics 24 (2009) 3108-3112.

[4] C. Stagni, C. Guiducci, L. Benini, B. Riccò, S. Carrara, B. Samorì, C. Paulus, M. Schienle, R. Thewes, IEEE Sensor Journal 7 (2007) 577-585.

[5] S. Carrara, A. Cavallini, Y. Leblebici, G. De Micheli, V. Bhalla, F. Valle, B. Samorì, L Benini, B. Riccò, I. Vikholm-Lundin, T. Munter, Microelectronics Journal, (2010) in press.

[6] S. Carrara, V. Bhalla, C. Stagni, L. Benini, A. Ferretti, F. Valle, A. Gallotta, B. Riccò, B. Samorì, Biosensors and Bioelectronics 24 (2009) 3425-3429.

[7] S. Carrara, V. Bhalla, C. Stagni, L. Benini, B. Riccò, B. Samorì, Surface Science 603 (2009) L75-L77.

[8] N. Pub, Nature biotechnology 24 (2006) 1151.

[9] A. Duparré, J. Ferre-Borrull, S. Gliech, G. Notni, J. Steinert, J. Bennett, Applied optics 41 (2002) 154-171.

10] H. Ouyang, C.C. Striemer, P.M. Fauchet, Applied Physics Letters 88 (2006) 163108

[11] T. Ichii, M. Urabe, T. Fukuma, K. Kobayashi, K. Matsushige, Hirofumi Yamada, Japanese Journal of Applied Physics 44 (7B) (2005) 5378.

[12] T. Ohzono, M. Fujihira, Physical Review B 62 (2000) 17055

[13] V. Bavastrello, V. Erokhin, S. Carrara, F. Sbrana, D. Ricci, C. Nicolini, Thin Solid Films 468 (2004) 17.

[14] R.L.C. Wang, H.J. Kruezer, M. Grunz, The Journal of Physical Chemistry B 101 (1997) 9767-9773.

[15] P. Harder, M. Grunz, R. Dahint, G.M. Whiteside, The Journal of Physical Chemistry B 102 (1998) 426-436. 